\title{
Development and achievement of software for cellular growth system
}

\author{
Min Shen \\ Chongqing Technology and business institute, \\ Chongqing hechuan, 401520, China \\ Email:simi_xuan@126.com
}

\begin{abstract}
Constant direct current stimulation has facilitation for cellular growth of many histiocytes. This paper primarily introduces systemic, detailed development and achievement of software for this system. The system can accomplish controlling action of peripheral circuitry through computer interface. The system can run stably, harmoniously and safely.
\end{abstract}

Keywords: Constant direct current-stimulation; Control system; detailed design

\section{Introduction}

Direct current stimulation can promote cell growth and lead to cell trend [1]. It is a widely applied in promoting Fracture Healing, developing of nerve fiber, treating of the infectious injury and promoting plant growth [2]. The commands from the cell growth and culture system based on direct current electric stimulation system are send to control the lower machine by the host computer to. Then the cell can be changed under different direct current electric stimulation. The data is analyzed and displayed by the software. This paper mainly describes the function design and implementation of the system software.

\section{System Requirement Analysis}

Requirement analysis is a very important stage in software life cycle. According to the requirement of system design, VB language is used as the programming language of the upper computer software control program. The system is operated on the Windows 2000 platform using the database Access. Because the change of data is not so fast the data acquisition rate is not required to be high. The asynchronous serial port communication is the way between the upper computer and the lower computer. The system is controlled by the software including transport protocol between the host computer and the lower computer, the data acquisition and other actions. It is proved that the scheme can achieve 
the goal and the error rate is very low.

\section{Functional requirements of database operation}

The operator can query, add, delete and modify the feature data based on the stimulation channel. At the same time the operator can set up the stimulation time and stimulation mode of each channel. The system can be manually adjusted according to the need so that it can be more flexible for real time calculation, storage, deleting stimulation parameters.

\section{System Design}

The relationship between the various modules of the system is indicated through program structure. The relationship between modules level is represented by system structure. The overall design diagram of the software system is shown in figure 1 .

\section{Detail Design}

Detailed design of the task is to achieve the specific details of each module design features. The detailed design method is structured. The programming design uses the top-down stepwise refinement design method, which is composed of three basic structures including the order, the branch and the repeat [3]. In this paper, the description of the tool is a graphical tool that is software program flow chart.Fig.1 shows the overall design diagram of the software system.

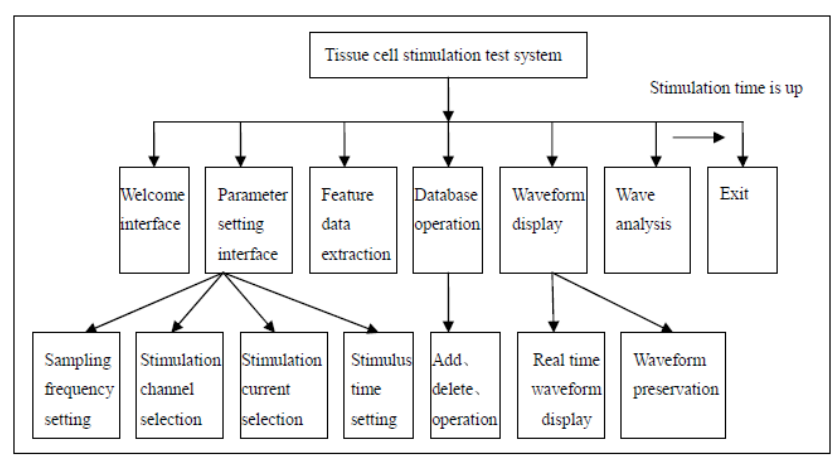

Fig.1 the overall design diagram of the software system

\section{Program Flow Chart}

Primary parameter of the interface is mainly the basic parameters of the serial ports of the whole 
system, sampling frequency and stimulus modality. These parameters mostly including serial port baud rate, serial buffer size setting. Fig.2 shows the parameter setting flow chart.

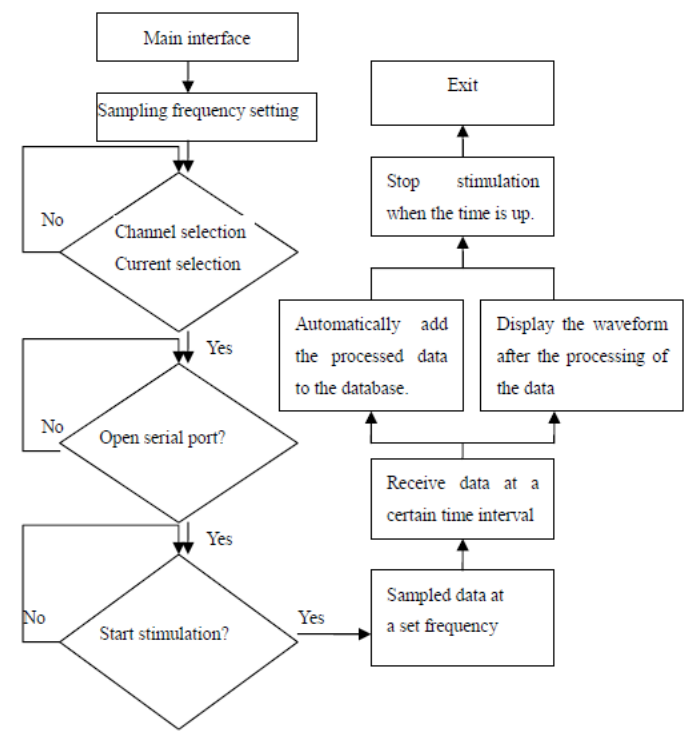

Fig.2 Parameter set flow chart

\section{Database Operation Function Design}

Database model has experienced the level of model, the network model that is today's widely used model from 1968[4]. The database in the system has some basic function .The first can be used to select, add, delete, modify stimulate the cell data. The second can be set up the parameters of the cells of the tissue, including the stimulation current, the stimulation time and the sampling frequency. The third is that the stimulation data of each tissue cells channel can be calculated and stored in real time. At the same time, some basic operations of the database can be carried out through the control platform. The VB software provides the ability of data access based on Jet Microsoft database. Jet engine is responsible for handling storage, retrieval, update data structure, and provides a powerful object-oriented DAO programming interface [5].The database operation flow chart is shown in Fig.3. 


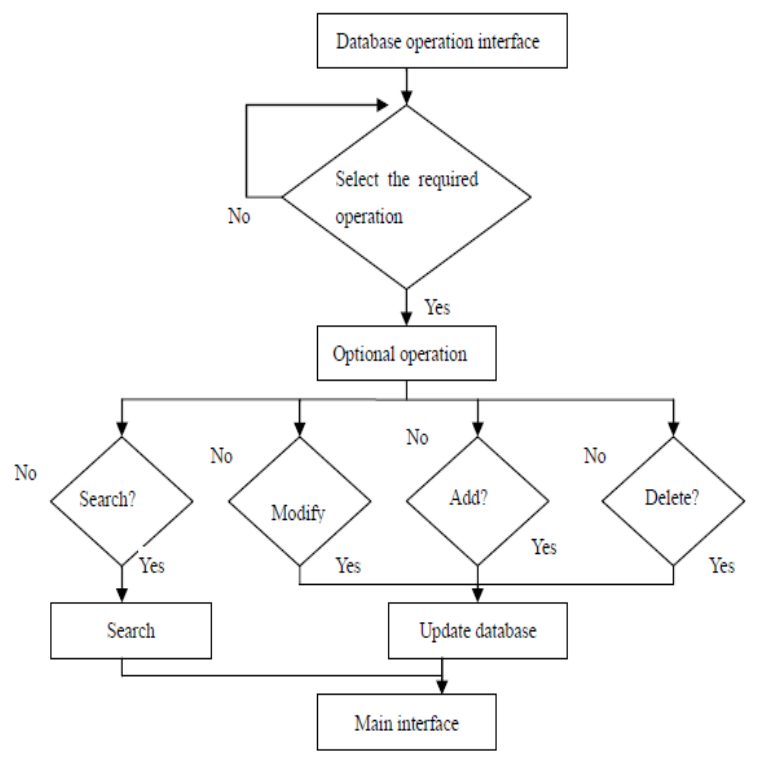

Fig. 3 the database operation flow of the software design

\section{Parameter Setting and Display Interface}

In order to the beautiful of the interface, other interface controls have been used in the software design except the VB software including the control. Many system interfaces compose the whole the tissue experimental system of direct current electrical stimulation. A few interfaces are simply described in the following.

Before the stimulation of the cell, it is necessary to set up the cell channel, the stimulation current and the time of stimulation. The "next" button can be pressed to enter the stimulating interface and carry out stimulating experiments after the parameters are set up. The user only needs to input data through a small keyboard when the time parameter of the stimulus is setting.

\section{Database Operation Interface}

To carry out data analysis and processing, to understand the whole process, the transformation of data. At the same time, the data also need to be saved, modify, add and delete, and so on. To achieve this function, we can achieve the most simple through the database. 


\section{Result}

When the system is debugged, the preliminary experiment is carried out with the electric resistance instead of tissue cells. When the system is debugged, the resistance of $10 \mathrm{k}$ replaces the cell replacement in preliminary experiment. The input control voltage is 5 volt. The table 1 show the contrast between the actual data and the theoretical value. The relative error range of the system is $4 \%$ $-7 \%$.

\begin{tabular}{|l|l|l|l|l|l|l|}
\hline $\mathrm{V}_{\mathrm{L}} \backslash \mathrm{I}_{\mathrm{L}}$ & $1 \mathrm{uA}$ & $10 \mathrm{uA}$ & $20 \mathrm{uA}$ & $50 \mathrm{uA}$ & $80 \mathrm{uA}$ & $100 \mathrm{uA}$ \\
\hline $\begin{array}{l}\mathrm{V} \text { (theoretical } \\
\text { value ) }\end{array}$ & 0.01 & 0.1 & 0.2 & 0.5 & 0.8 & 1.0 \\
\hline $\mathrm{V}$ (actual value) & 0.0093 & 0.104 & 0.1966 & 0.4889 & 0.7885 & 0.9806 \\
\hline absolute error & -0.0007 & 0.004 & $\begin{array}{l}-0.003 \\
2\end{array}$ & -0.0111 & -0.0115 & -0.0194 \\
\hline relative error & $-7 \%$ & $4 \%$ & $-1.6 \%$ & $-2.22 \%$ & $-1.44 \%$ & $-1.94 \%$ \\
\hline
\end{tabular}

Tab1: the comparison between experimental data and theoretical data

\section{Discussion}

The preliminary experiment of the system is carried out by using the electric resistance instead of tissue cells. The growth trend of the tissue cells can be obtained with the stimulation of different micro current when the tissue cells are used to carry out the experiment. Through the comprehensive analysis and calculation of the growth trend, It is found that the stimulation current intensity and the time of stimulation are suitable for the growth of tissue cells.

\section{Acknowledgments}

This work is supported by the Chongqing Education Commission under Grant No.KJ1503901 and No.KJ1403808.

\section{Reference}

[1] Zhang Jingru. Physiology [M], Beijing: People's Health Publishing House 2002.

[2] Wang Qian. An experimental study on the promotion of electrical stimulation to osteoblast adhesion characteristics [J]. Journal of Jinan University. February 2000, 21(1): 46-47

[3] Wang Chun-sen. System designer (senior programmer) tutorial[M]. Beijing: Tsinghua University press.2001 
[4] Yao Wei. VisualBasic database development and engineering examples [M]. People's Posts and Telecommunications Press.2003, July.

[5] Tan Haoqiang. VisualBasic computer programming. Tsinghua University press.2001

[6] Fan Yi-zhi. VisualBasic and RS232 serial communication control. Chinese Youth Press, January 2001. 